\title{
Barangay Disaster Preparedness Monitoring Web Application System
}

\author{
Yvette M. Garcia \\ AMA University, Philippines
}

\author{
Dennis B. Gonzales, PhD \\ University of the East, \\ Philippines
}

\author{
Ruel Michael Gilbang \\ HCT-IT, Muscat, Oman
}

\author{
Mary Ann C. Paguio, PhD \\ HCT-IT, Muscat, Oman
}

\begin{abstract}
The Barangay Disaster Preparedness Monitoring Web Application System is a web application system that will be used by the Department of Interior and Local Government in the Philippines. It is used to standardize data collection of barangay disaster preparedness information at the barangay level, provide a more efficient reporting system for the DILG Field Officers from the cities and municipalities and to have a monitoring tool and automatic consolidation of data at the national level. This system uses an open source Relational Database Management System (RDBMS) and adapts the Philippine Standard Geographic Code data at the national level. This system will provide the DILG management a realtime scenario on barangay preparedness through data visualization.
\end{abstract}

\section{Keywords}

Disaster Preparedness, Community-Based Disaster Risk, Reduction and Management (CBDRRM), Data Visualization, PSGC and Relational Database

\section{INTRODUCTION}

The Philippines is susceptible to disaster geographically because it is located in the Pacific Ring of Fire and situated near the equator. Given this reality, disaster preparedness has to be a continuous effort for all sectors in the Philippine society. Data and information are very essential in disaster preparedness. This is the baseline to facilitate proper coordination and timely response in the event of a disaster. Data is very critical when lives are at stake and time is of the essence. An unreliable, incomplete, inaccessible and outdated set of information is detrimental to the country. Every year, the Philippines is hit by severe typhoons, destructive earthquakes, and occasionally, volcanic eruptions. Given this scenario, it is but necessary to build and maintain a database on disaster preparedness and have access to reliable and upto-date information for all stakeholders involved to be used for disaster risk reduction and management.

\section{BACKGROUND OF THE STUDY}

In the National Disaster Risk Reduction Management Plan (NDRRMP) 2011- 2028, the Department of Interior and Local Government (DILG) is the head agency responsible in the overall task of Disaster Preparedness. The National Barangay Operations Office of the DILG was given primary responsibility of monitoring and evaluating the institutionalization of the community-based disaster risk reduction and management (CBDRRM). It is also tasked to do Barangay Disaster Preparedness Profiling to assess the readiness of barangays during a disaster. Data collection is undertaken and accomplished by the DILG Field Officers via a data capture form in paper format and submits it to the City and Municipality Offices and then submits it for consolidation at the DILG Central Office. Given this method of data collection, it is very difficult to see the overall picture on the level of readiness of barangays. The DILG and the national government have no basis in developing programs and projects that address disaster related issues as well as in determining the gaps and areas for improvement. To address this problem, there is a need for the existence of a database on Barangay Disaster Preparedness Profile that will help the local and national government in their decision-making processes.

This study will develop a relational database for the barangay disaster preparedness using an open source Relational Database Management System (RDBMS). The Barangay Disaster Preparedness Web Application System that will be developed aims to standardize data collection at the barangay level and provide a more efficient reporting system for the DILG Field Officers from the cities and municipalities, which is expected to improve the monitoring and consolidating of data at the national level. This system will provide the DILG management a real-time scenario and information on the barangay's preparedness through data visualization.

\section{REVIEW OF RELATED LITERATURE}

\subsection{Local Literature}

Ignacio and Henry (2013) performed a comprehensive social vulnerability assessment for Philippine coastal communities exposed to coastal river flood hazard using the 2007 Census Population and Housing. The coverage of the study is the entire Philippines from the Provinces down to the barangay. The Philippine population data from the 2000 and 2010 used in the research uses the Philippine Standard Geographic Codes. This result to the possibility to visualize geographically the distribution of vulnerability-related data down to the barangay level which could be basis for decisionmaking in government. [1]

The Maternal Geographic Information System (GIS) applications undertaking utilize a standard coding system. It was created to recognize all the hospitals and rural health units (RHU) within the range of the framework. The HF_CODE was the name given to the coding system which means the "Health Facility Code." The same coding system was adopted for the Philippine database in Health Mapper, an investigation and mapping system for infectious disease created by the World Health organization (WHO) and the United Nations International Children's Emergency Fund (UNICEF). Its structure adapted the Philippine standard geographic code (PSGC). The primary level is composed of a 
6-digit PSGC code created by the National Statistical Coordination Board (NSCB) which is an organized classification of topographical territories in the Philippines. This classification depends on the four established levels of geographical political subdivisions of the Philippines, region, province, city / municipality and barangay. The PSGC is being adopted as a standard coding system by the Inter Agency Task Force on Geographic Information (IATFGI) and applied by the National Mapping and Resource Information Administration (NAMRIA) as part of its GIS improvement ventures. (Leonardo, 2007) [2]

Although there is a proposed bill under the House of Representatives on the compulsory adoption of Free Open Source Software (FOSS), open standards and open formats in all national agencies have not yet been allowed. The CICT prefers to keep an "open choice" procedure giving national agencies a chance to have the final say on which innovation they need to utilize. In the case of the DILG, there is the current Policy on Development of Application Systems and Database Management on the use of open source framework in the development of systems.

\subsection{Foreign Literature}

It is important to acquire data and information for risk management. It is essential to combine the hydrological analysis and risk assessment that are supported by data collection and archiving. The data should be collected locally and institutionally. (Kuribayashi, 2015) [3]

In the "Survey of Data Management and Analysis in Disaster Situations," it introduces a thorough study of endeavors in applying and advancing the administration and examination of information to serve disaster management circumstances. The information was organized on the Computer Science discipline: data integration and ingestion, data extraction, data recovery, data filtering, data mining and decision support. Likewise, the future examination headings for information system seek to advance the learning of applied data management and analysis in disaster administration. (Chen, S., et al, 2010) [4]

A technical report of the worldwide and regional patterns of water-related calamities and the social effects in understanding the future necessities to establishes a standardized indicator. This helps with the identification of fundamental threats from water-related calamities, execute policy examination, and assess the usefulness of approved measures in water hazard mitigation. The result demonstrated in tabular and graphic forms for each type of water related catastrophe allows the user to assess the present state of the global and regional developments that are often selected as valuable indicators to monitor the progress in disaster mitigation. (Merabtene, T. what's more, Yoshitani, J., 2005) [5]

\subsection{Local Studies}

The case study on "Barangay Government Disaster Preparedness: The case of Typhoon Sendong affected Iligan Communities" reveals that most of barangays are not prepared for disasters. One of the enumerated causes was the absence of proper information-based system. In this study, it emphasized how the barangays should establish communitybased disaster information system (Viloria, 2014). [6]

The proponent wants to develop a system that automates some of the processes that the organization is doing. The elimination of the use of paper aims to lessen the expenses in supplies. The project that will be developed aims to assist in the decision making of executives in the DILG. This should eliminate redundancies when it comes to reporting and reduce the manual counting and computing of the reports which is very time-consuming. (Ledesma, 2013) [7]

\subsection{Foreign Studies}

According to a study "Moving towards Harmonization of Disaster Data: A Study of Six Asian Databases," they concluded that there is an urgent need for robust field methodologies to estimate the number of dead, injured and affected people. They also decided that guidelines are essential for the use of the national governments, international organizations dealing with policy making, and relief agencies. It further recommends that there should be a standard methodology that every agency can use to clarify raw data, which could become a source for misguided policy and erroneous decision-making (Below et. al, 2010). [8]

It stressed that the growth and feasibility of a framework is dependent on an understanding and establishment of a national disaster management database capturing the various scope and activities related to national disaster risk management. Creation of an effective database at a national level is a necessity, along with technical structures and potential solutions. This national database gives a common structure of reference for all provincial and local agencies and sets up the framework for administering and organizing the data required to strengthen the disaster risk management activities of responsible organization. Fundamental composition of national database structure are hazard appraisal mapping, vulnerability assessment, population distribution, infrastructure, lifelines, rescue facilities, logistics and transportation, human and material rescue resources, and communication infrastructure. It is recommended that there must be a database structure that strengthens the national and regional organizations on the process of capacity building, hardware, software, network, WebGIS for decision makers to use these reliable disaster information to assist them in making important decisions. (Pareta, 2011). [9]

According to Assilzadeh (n.d) of the University Putra Malaysia, to achieve success in disaster management system, the creation of natural disaster information and data administration framework ought to be given prime importance among program initiators, leaders, and directors at national and local levels, expert groups, funding organizations, NGOs and voluntary association. National level institutional mechanism should be upgraded to help and assist in formulating short and long-term disaster preparedness, mitigation and prevention techniques. [10]

The study stated that there is an increased attention given to issues related to disaster management, which aims to adopt measures to prevent and reduce the risks of extreme events developing into catastrophes. It also stated that the process used to create, store, and share information is a key factor in facilitating decision-making. It also emphasized that the availability and quality of information should be obtained from the right people and should be sent in the proper way and at an appropriate time to contribute to the effectiveness of the services performed by Emergency Agencies (EA) (Gill and Bunker, 2012). [11]

The study on the "Complex Emergency Database (CEDAT): A Global Repository of Small-Scale Surveys on Nutrition, Health and Mortality," remains the essential source of nutrition and health surveys from conflict affected populations. The database provides the decision maker evidence-based information for potential policy settings and 
for the monitoring of trends specifically on hard to reach population. (Altare, 2014). [12]

The utilization of decision-support techniques like data visualization can lead to better execution in management decisions. It can enhance the effectiveness of created solutions and can assist in handling new types of issues that have not been addressed recently. It was utilized in the health care services based on the recommendations of the public health management.

On the other hand, open source could be utilized as an effective instrument to meet the twin problems of poverty alleviation and economic down turn similar to the Shana disaster management system. This has been acknowledged as an appropriate approach in managing future disasters that allows governments to adopt free and open source software in their individual ICT policies. (Pandey et. al., 2013) [13]

\subsection{Synthesis}

This project is about the development of a Web Application System on Barangay Disaster Preparedness Monitoring. The pertinent information for this paper was gathered from various sources. The related studies and literature presented have helped the proponent in the conceptualization of the project and provided wider insights into the similarities of existing projects.

In the case study of Leonardo (2007) and Ignacio \& Henry (2013), both used the Philippine Standard Geographic Code, which is an organized classification of topographical territories in the Philippines. This classification is dependent on the four established levels of geographical political subdivisions of the Philippines--- the region, the province, city/municipality and barangay. This results in the geographic visualization of data in the local level anywhere in the country, which can significantly influence decision-making at all levels of government.

According to Viloria (2014), the need for a database structure and information management system are important. Moreover, there should be a process used to create, store and share information, which is the key factor in facilitating decision-making on disaster risk reduction on all levels.

In the manner of data collection, the system developed by De La Salle University on Crime Intelligence System gave a useful idea to the proponent that focused on automating the process of reporting, eliminating the use of paper forms, and avoiding the manual counting and computing of reports that will lessen redundancies when it comes to reporting.

According to Chiara Altare (2014), the use of decisionsupport techniques like data visualization of information can lead to better execution in management decision. For Merabtene , T. and Yoshitani, J. (2005), the result of their survey was presented in tabular and graphic forms for each type of water related catastrophe which allows the user to assess the present state of the global and regional developments which are often selected as valuable indicators to monitor the progress in disaster mitigation.

\section{PROJECT OBJECTIVES}

The general objective of this study is to design and develop a web application of Barangay Disaster Preparedness Monitoring System for data collection.

Specifically, this study seeks to answer the following objectives:
1. To design a framework on data collection that will provide access on information at the National, Regional, City, Municipality and Barangay levels;

2. To establish a database that will capture information from the Barangay Disaster Preparedness Profile using open-source relational database management system and will adapt the Philippine Standard Geographic Codes;

3. To develop a monitoring tool for management on the status of compliance by the barangays in terms of disaster preparedness;

4. To evaluate the system based on ISO 9126 standard which uses the product quality model that emphasizes on functionality, efficiency, usability, reliability and security.

\section{SCOPE AND DELIMITATION}

This project will create a central repository for the data and profiles of the barangays on disaster preparedness. This repository includes information on:

1. DRRM committee members,

2. Data on DRRM plans formulated and the funding available,

3. Risk assessment data and early warning system,

4. Public information and education initiatives,

5. Preparedness for effective response and early recovery data such as evacuation centers and available equipment and resources.

The DILG Field Officers shall access the system using their log-in credentials for data accountability. This project is expected to assist in analyzing the data submitted through real-time reports and actual visualization that the DILG management can access to help them in their decision-making process.

The Barangay Disaster Preparedness Monitoring Web Application System is composed of modules which include:

\subsection{General Information Module}

In this module, the user will add or update information related to demographics, hazard prone areas, and vulnerable members of the communities.

\subsection{Disaster Preparedness Indicators Module}

In this module, the user will add or update the information that will capture indicators on the following: Organizational Requisites, Risk Assessment and Early Warning, Public Information and Education Initiatives and Preparedness for Effective Response and Early Recovery.

\subsection{Monitoring Module}

This module will monitor submission of data from the Local Government Units grouped according to Region and Provinces.

\subsection{System Administration Module}

In this module, user administration is performed. The user with this privilege can accept registered users and classify them according to user access level. Deletion and blocking of accounts are also performed in this module. File maintenance is also performed in this module. 


\subsection{Report Module}

In this module, report requirements can be generated. Data Visualization views can be accessed.

The Barangay Disaster Preparedness Web Application System does not include a geographic representation of local government units for its data visualization. The system is also non-mobile compatible and not accessible to mobile devices. Users can only access the system through a desktop browser.

\section{SIGNIFICANCE OF THE STUDY}

The following beneficiaries of the system are as follow:

DILG Field Officers. This project will ease the work of the DILG Field Officers because they do not need to write information in the Data Capture Form and retype all the data gathered in electronic form for submission to the Central Office.

DILG Executives and Other Stakeholders. This project will provide the DILG management access to real-time data whenever they need them. They will have an overall depiction of the readiness of the barangays, which will help them in effectively deciding what kind of assistance a barangay needs such as capacity development, procurement of equipment and resources, funding, planning and coordination process, among others.

Parents / Teachers / Students and the General Public. This project will greatly benefit our parents, teachers, students and the general public. Though they are not the direct users of the system, they can still benefit from it because they are also affected during disasters. This ready database can assist in the reduction of casualties by having information that the Executive Officials and Local Officials can use. These officials can access this database for proper coordination in the Barangays to promote the safety of their constituents and to give further assistance during disasters.

Civil Society Organization. As an active partner of national agencies of government civil society organizations can utilize the information that can be generated in the system in their participatory activities in relation to disaster preparedness.

Funding Institutions. The information from the database can be a reference for funding institutions on what LGU and barangays need in relation to disaster preparedness that may serve as reference for possible financial assistance.

\section{RESULTS AND DISCUSSION}

This chapter presents how the system provides access on national, regional, city, municipality and barangay levels. The open-source relational database is presented using the Philippine Standard Geographic.

Also, the monitoring tool and data visualization reports is demonstrated, which is used by management to monitor status of compliance of barangays in terms of disaster preparedness and to support decision making policies of DILG.

The architecture and design of the application are based on the proponent's ideas, concepts, vision, panel's inputs, and adviser's comments. The suggestions and requirements of the respondents are also considered. Likewise, the research and information gathered were applied in the development of the system.

\subsection{Presentation of Access level}

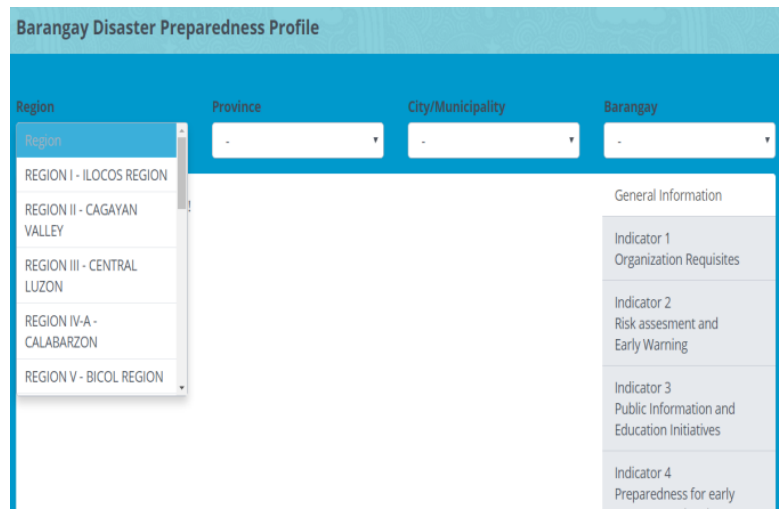

Figure 1: National Access level

Figure 1 shows the national access level. It is provided to users with an Administrator user account. With an administrator account, users have access to the data or information on a national scale.

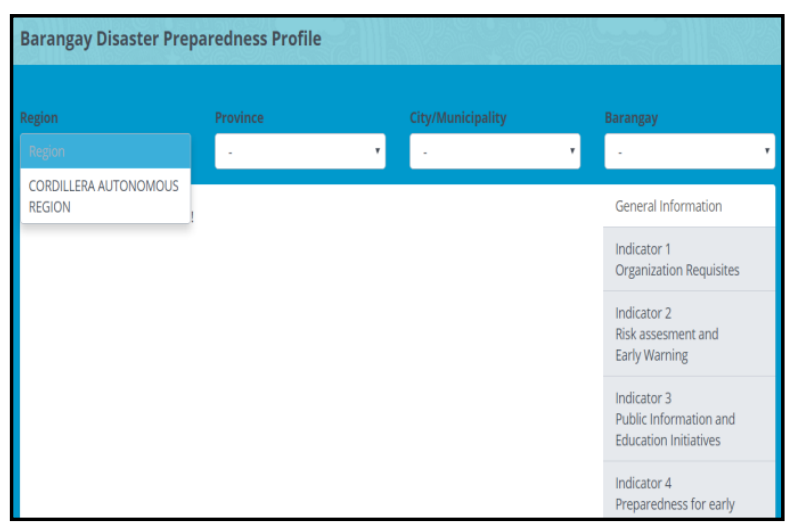

Figure 2: Regional Access level

Figure 2 shows the regional access level. This access is given to users with a regional user account. With a regional account, users have access to the data or information on a regional scale.

Figure 3 shows the city / municipality access level. This access is given to a city/municipality user account. A user with this account has access to the data or information on a city / municipality scale. This access level give users the right to update the information of his/her designated city or municipality. The barangay disaster profile under the city and municipality can be updated in this access level, as shown in Figure 4.

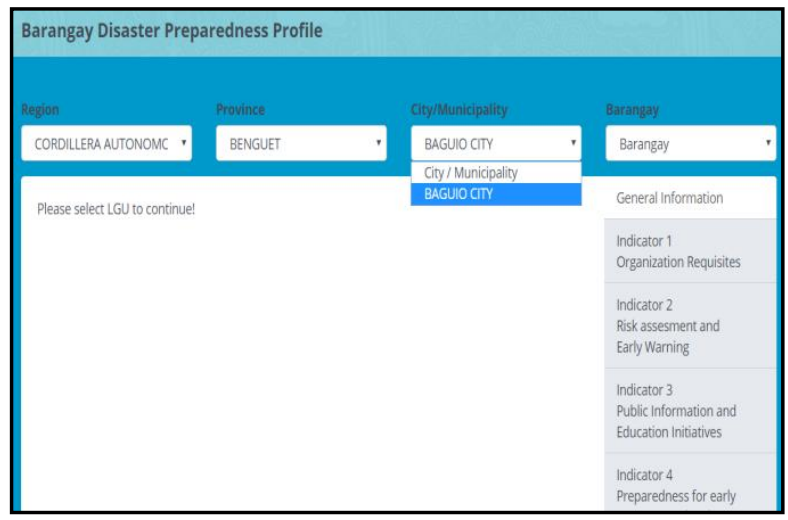

Figure 3: City / Municipality Access level 


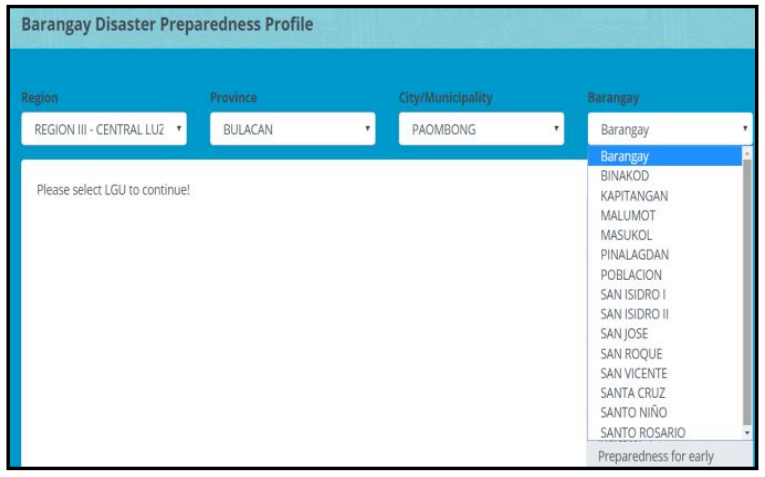

Figure 4: City / Municipality Access level - List of Barangays

The available data for the City / Municipality level are the Barangay general information, organization requisites, risk assessment early warning, public and education initiative and preparedness for early response and recovery. These informations can only be changed by the user with access to the City / Municipality level.

\subsection{Presentation of the relational database design using the PSGC}

Figure 5 shows the entity relationship of Region, Province, City / Municipality and Barangay tables. The data from region, province, city/municipality and barangay levels adapt the Philippine Standard Geographic Codes.

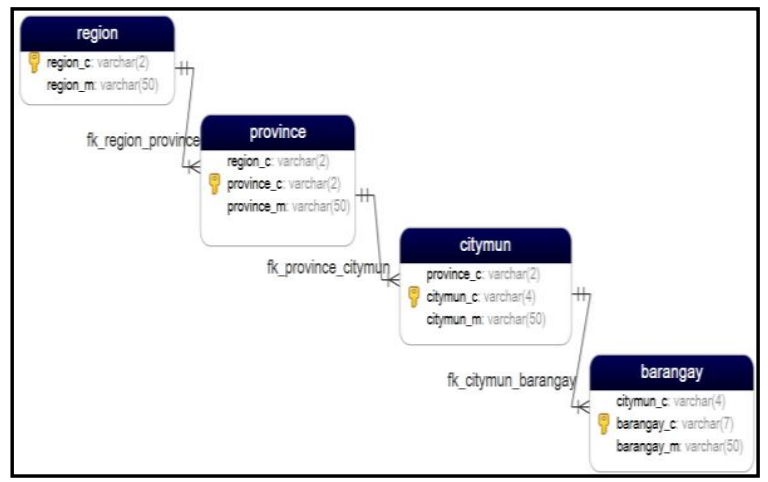

Figure 5: Entity relationship of Region, Province, City / Municipality and Barangay tables

\subsection{Presentation of Monitoring Tool and Data Visualization Reports}

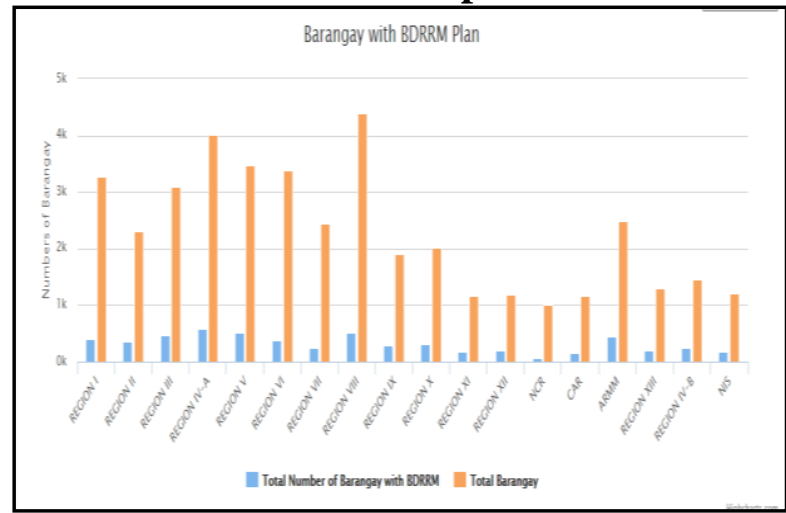

Figure 6: National - Barangay with BDRRM Plan
Figure 6 shows the national aggregated data on the total number of Barangays with Barangay Disaster Risk and Reduction Management (DRRM) Plan. This shows the distribution of the number of barangays with BDRRM Plan according to Regions. It also reflects the total number of barangay for each Region, highlighting the figure on the status of barangay accomplishment in terms of preparation for the BDRRM Plan.

The figure also shows which regions have the highest and lowest number of barangays.

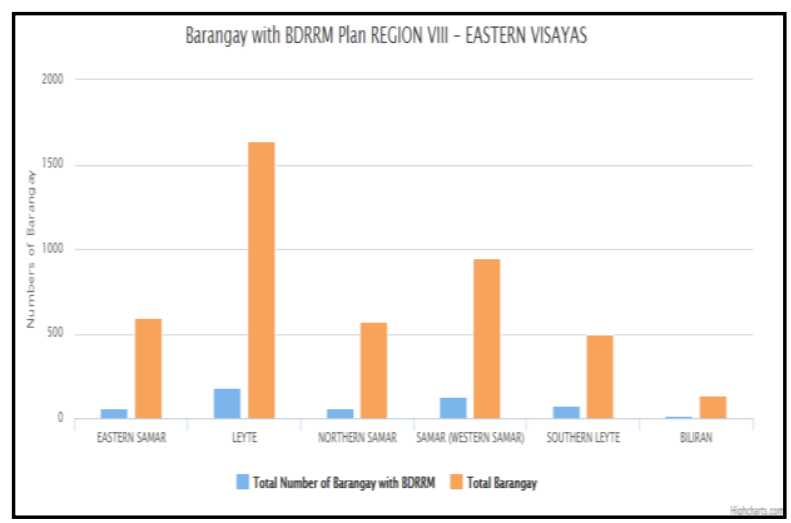

Figure 7: Region-wide - Barangay with BDRRM Plan

Figure 7 shows the Region-wide aggregated data on the total number of Barangays with Barangay Disaster Risk and Reduction Management (DRRM) Plan. This shows the distribution of the number of barangays with BDRRM Plan according to Province. It also reflects the total number of barangays for each Province, focusing on the figure of the status of the barangay accomplishment in terms of BDRRM Plan preparation at the region-wide level.

In the graph of Figure 7, it also shows the provinces under selected regions. The total number of barangays with BDRRM Plan and the total number of barangays are aggregated data wherein it counts the barangays with entries on BDRRM Plan, while the label total barangays count the number of barangays within the particular city or municipality.

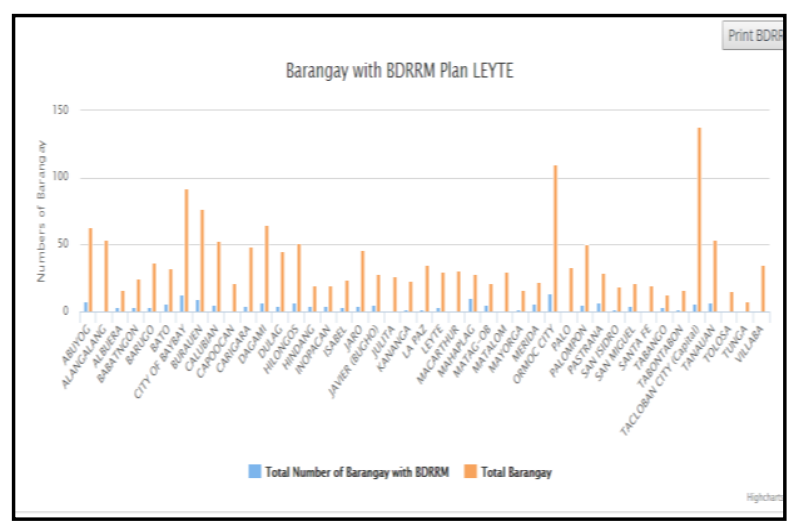

Figure 8: Province-wide - Barangay with BDRRM Plan

Figure 8 as shown below, presents the Province-wide aggregated data on the total number of Barangays with Barangay Disaster Risk and Reduction Management (DRRM) Plan. This shows the distribution on the number of barangays with BDRRM Plan according to City and Municipality. It also reflects the total number of barangays for each City and 
Municipality, highlighted in the figure on the status of barangay accomplishments in terms of the preparation and implementation of the BDRRM Plan.

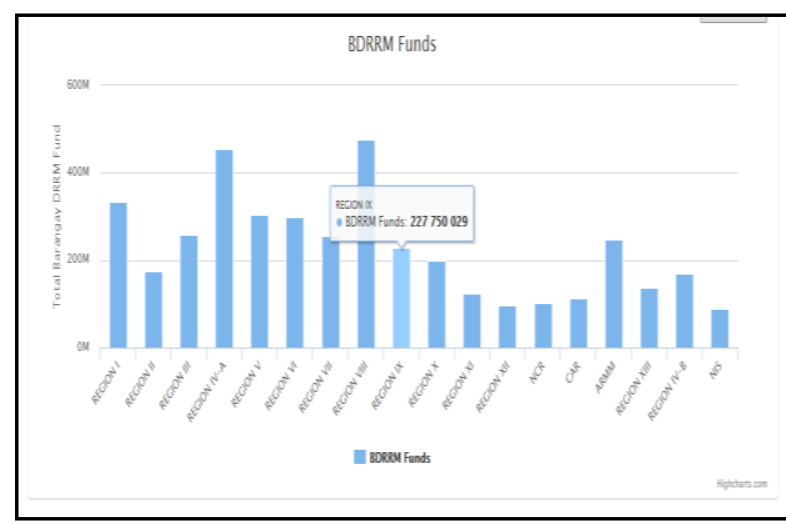

Figure 9: National - BDRRM Funds

Figure 9 shows the National aggregated data on the total funds allocated by the barangays for Disaster Risk and Reduction Management (BDRRM). This reflects fund allocation distributed according to Regions.

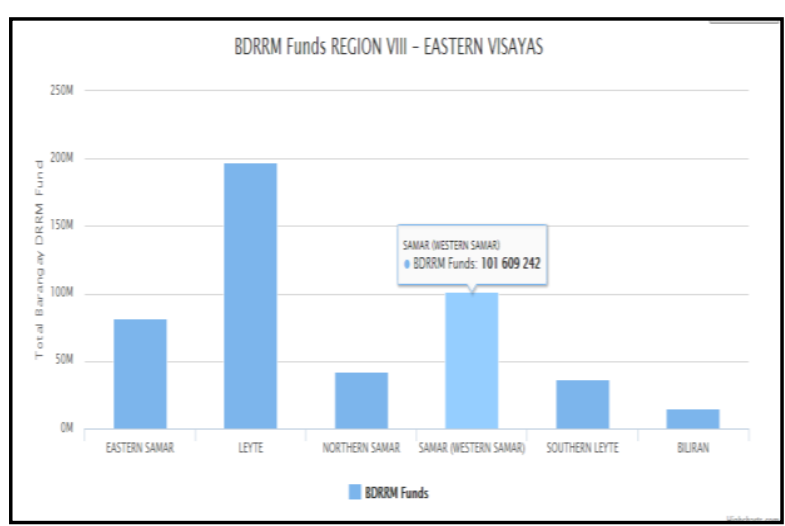

Figure 10: Region-wide - BDRRM Funds

Figure 10 presents the Region-wide aggregated data on the total funds allocated by the barangays for Disaster Risk and Reduction Management (BDRRM). This shows the fund allocation distributed according to Province.

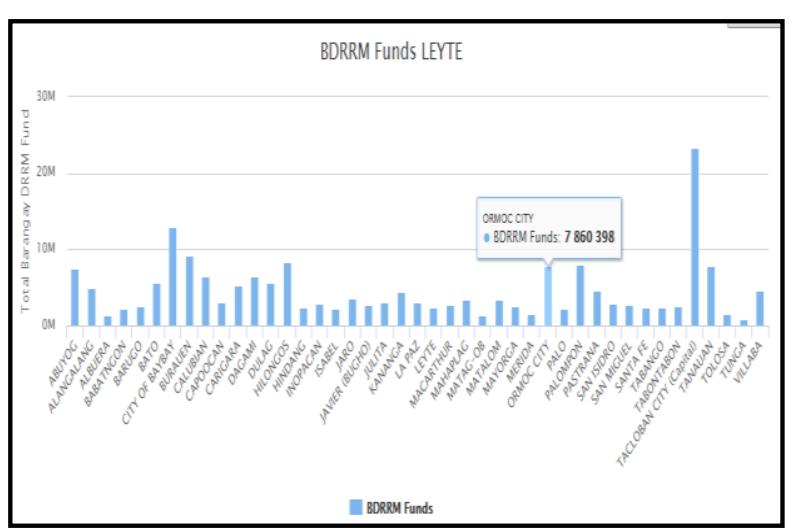

Figure 11: Province-wide - BDRRM Funds

Figure 11 illustrates the Province-wide aggregated data on the total funds allocated by the barangays for Disaster Risk and Reduction Management (BDRRM). This reflects fund allocation distributed according to Cities and Municipalities.
The graph above displays which city or municipality has the highest fund allocation for disaster preparedness and which city or municipality has the lowest fund allocation for disaster preparedness.

The graph on Figure 11 exhibits the aggregated data of fund allocation from barangays of the particular city or municipality. The graph report city/municipality-wide can also be generated to show the distribution of fund allocation according to barangay, which displays the fund allocation per barangay.

Figure 12 illustrates the National aggregated data of barangay population that are at risk according to region. It presents the total population that could be affected by a disaster at a region level. This report also reflects the total affected population according to the type of disaster. The example shows the total population at risk during a Multi-hazard type of disaster.

The national population at risk report displays a graph of aggregated data of population at risk in all barangays within the region.

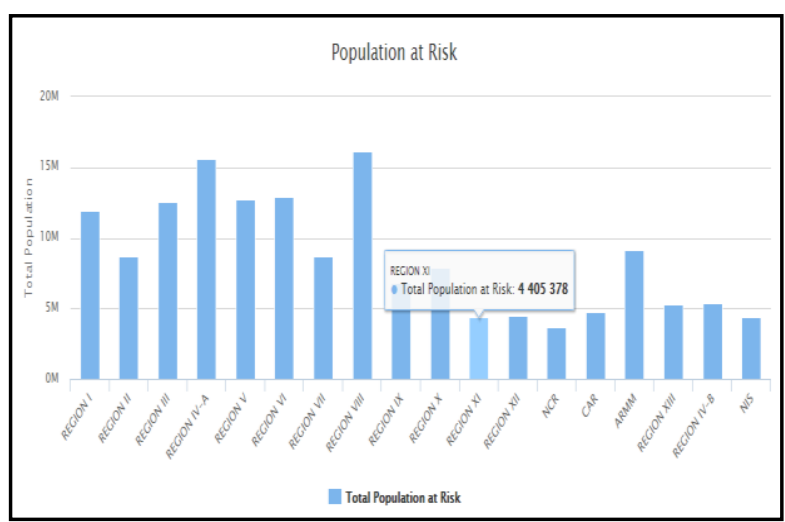

Figure 12: National - Population at Risk

Figure 13 demonstrates the Region-wide aggregated data of barangay on population at risk. It shows the total population that could be affected by a disaster according to the province composition of the region. The reflected total population at risk for the provinces is the aggregated data of all barangays within the province.

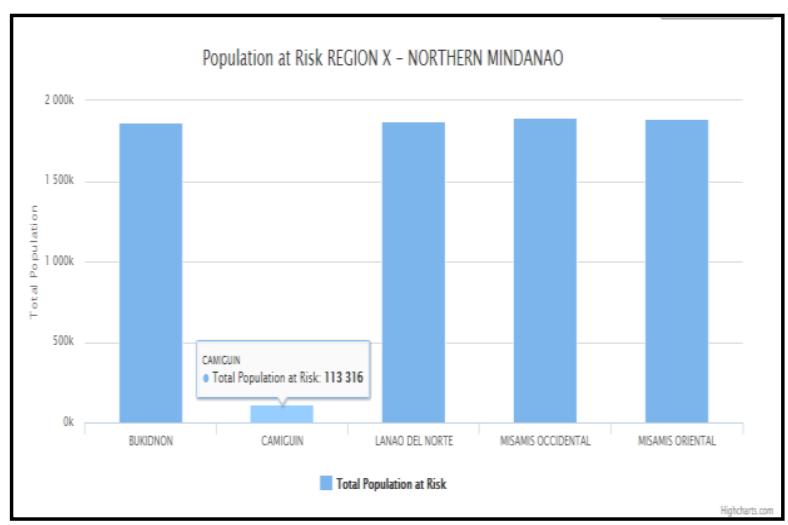

Figure 13: Region-wide - Population at Risk

Figure 14 shows the Province-wide aggregated data of barangay on population at risk. It reveals the total population that could be affected by a disaster according to city / municipality composition of the province. The reflected total population at risk is the aggregated data of all barangays within the city / municipality. 


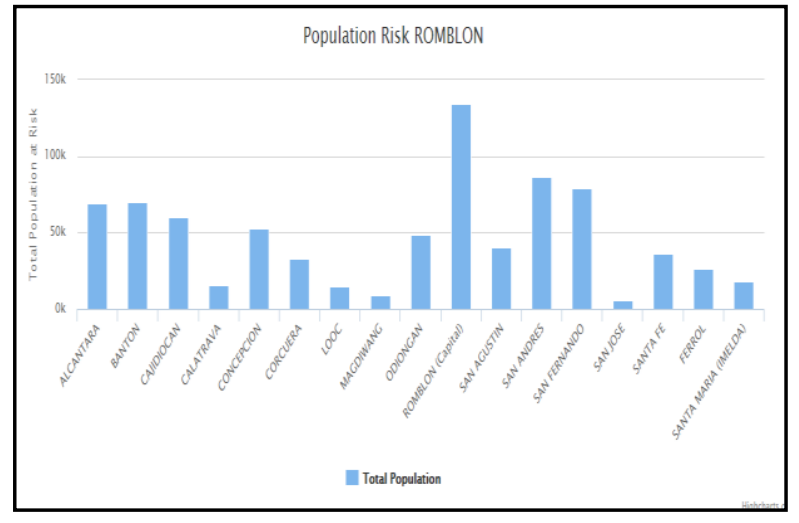

Figure 14: Province-wide - Population at Risk

\section{SUMMARY, CONCLUSION, AND RECOMMENDATIONS}

\subsection{Summary}

Disaster Preparedness is a must for everyone. For the national government, the National Barangay Operations Office of the Department of the Interior and Local Government is given primary responsibility in the community-based disaster risk reduction and management (CBDRRM). It is also given the task to implement the Barangay Disaster Preparedness Profiling to assess the readiness of barangays during a disaster.

Developing a Barangay Disaster Preparedness Monitoring Web Application System for the National Barangay Operations Office of DILG is the primary objective of this study. It also seeks to provide a relational database that will be the central repository of data for barangay profiles on disaster preparedness, DRRM committee members, DRRM plans formulated, funding, risk assessment data, early warning system, public information and education initiatives, preparedness for effective response, and early recovery data like evacuation centers and available equipment and resources. This presents a standard means of data collection from the local government units and barangays and can be used as a tool for analyzing data through visualization for the DILG Executives.

\subsection{Conclusions}

The Barangay Disaster Preparedness Monitoring Web Application System was developed as a means for data collection and central repository of disaster preparedness information of the barangays in the Philippines setting. It shows the possibility of adapting the Philippine Standard Geographic Codes to represent and aggregate data of barangay disaster profile on a national, regional, province, city and municipality level. The data visualization reports presented in this study offers the higher management with a convenient method to monitor compliance of barangays on information related to disaster preparedness. It shows the aggregated data on a national, regional, province, city and municipality level that could support management in decision making policies. The data generated provided information for developing programs and projects that address disaster related issues as well as in determining gap areas and areas for improvement.

\subsection{Recommendations}

The Barangay Disaster Preparedness Web Application System was developed to have a central repository of data on disaster preparedness. Data visualization presented shows that at the level of national management, it helps in the monitoring of compliance of disaster preparedness of the barangays. However, the study lacks the geographical representation that would show the relation of barangay disaster preparedness data against the existing hazard geographical maps of the Philippines. Further studies are necessary in the long term to deal with the questions on: How are the barangays are prone to disaster? Are they prepared for such disasters? And how should they prepare in the future? These are the other questions that should be addressed in future studies. Therefore, it is recommended that this study can serve as a basis to help the management in determining the barangay's readiness in the event of a disaster.

\section{REFERENCES}

[1] Ignacio, A., Henry, S (2013). Assessing changes in village-level social vulnerability based on census data, Available from International Union for the Scientific Study of Population (http://iussp.org/)

[2] Leonardo, L, (2007). Geographical information systems in health research and services delivery in the Philippines, Available from Geospatial Health Website (http://www.geospatialhealth.net/)

[3] Kuribayashi, (2015). Special session for international flood initiative and international drought initiative. Available from International Flood Initiative Website (http://www.ifi-home.info/)

[4] Chen, S., et al (2010). Survey of data management and analysis in disaster situations, Available from Elsevier Website, Journal of Systems and Software (http://www.elsevier.com/locate/jss)

[5] Merabtene, T., Yoshitani, J.(2005) Technical report on global trends of water-related disasters, Available from Global Centre of Excellence for Water Hazard and Risk Management (http://www.icharm.pwri.go.jp/)

[6] Viloria, L. (2014). Barangay government disaster preparedness: The case of typhoon sendong affected iligan communities. Available from Philippine Sociological Society Website (http://philippinesociology.com/)

[7] Ledesma, B T. (2013). Crime intelligence system, Available from De La Salle University Website (http://www.dlsu.edu.ph/)

[8] Below R., et. al, (2010). Moving towards harmonization of disaster data: a study of six Asian databases, Available from EM-DAT the International Disaster Database Website (http://www.emdat.be/)

[9] Pareta, K. (2011). Developing a national database framework for natural disaster risk management. Available from International Society for Photogrammetry and Remote Sensing Website (www.isprs.org)

[10] Assilzadeh H., Mansor, S.B, Natural disaster data and information management system, Institute of Advanced Technology (ITMA), University Putra Malaysia, Available from United Nations Public Administration Network (www.unpan.org)

[11] Gill, A., Bunker, D (2012). Crowd Sourcing Challenges Assessment Index for Disaster Management, Available from Open Publications of UTS Scholars Website (https://opus.lib.uts.edu.au/) 
[12] Altare, C., Guha-Sapir, D (2014). The Complex Emergency Database: A Global Repository of SmallScale Surveys on Nutrition, Health and Mortality, Available from The Public Library of Science (PLOS) (https://www.plos.org/publications/journals/)

[13] Directorate of relief, disaster preparedness and refugees, office of the prime minister. (2010). The Republic of Uganda National Policy for Disaster Preparedness and
Management, Available from Prevention Web Website, a project of UN Office for Disaster Risk Reduction (UNISDR) (http://www.preventionweb.net/english/)

[14] Pandey, S, Tyagi, V, Pathak, K (2013). Role of Open Source Software and ICT in Disaster Management, Available from International Journal of Scientific and Engineering Research (http://xplore.ijser.org/) 